Referencia para citar este artículo: Rocha, J., \& Rozek, M. (2018). Quando o aprender na escola é (im)possibilidade. Revista Latinoamericana de Ciencias Sociales, Niñez y Juventud, 16(1), 361-373. doi:10.11600/1692715x.16122

\title{
Quando o aprender na escola é (im) possibilidade*
}

\author{
JULIANA DOS SANTOS ROCHA ** \\ Pontifícia Universidade Católica do Rio Grande do Sul, Brasil. \\ MARLENE ROZEK ${ }^{* * *}$ \\ Pontifícia Universidade Católica do Rio Grande do Sul, Brasil.
}

\section{Artículo recibido en septiembre 6 de 2016; artículo aceptado en octubre 20 de 2016 (Eds.)}

- Resumo (analítico): o presente texto é parte dos resultados de uma pesquisa de Mestrado em Educação e se propõe a refletir sobre os sentidos subjetivos e a relação de jovens que participaram do estudo com a instituição escolar. Participaram da pesquisa 10 sujeitos, de 14 a 18 anos, moradores da cidade de Porto Alegre-Brasil. Foram utilizados, para a coleta de dados, dois grupos focais e a técnica projetiva psicopedagógica, aplicada individualmente. Em geral, é possível inferir que os sujeitos têm dificuldade de se perceberem como aprendentes devido aos percalços encontrados no espaço escolar. Os jovens relatam não se sentir parte da escola, não ter suas aprendizagens reconhecidas e, ainda, apresentam dificuldade de estabelecer vínculos saudáveis com os professores e professoras.

Palavras-chave: aprendizagem, juventudes, escola (Thesaurus de Ciências Sociais da Unesco).

\section{Cuando el aprendizaje en la comunidad escolar se convierte en una (im)posibilidad}

- Resumen (analítico): este texto constituye parte de los resultados de una investigación realizada en el Programa de Maestría en Educación y tiene como objetivo reflexionar sobre los sentidos o significados subjetivos y sobre la relación de los jóvenes quienes participaron en dicho estudio en la institución escolar. Diez jóvenes de la ciudad de Porto Alegre, Brasil, -entre los 14 y 18 años de edad-participaron en la investigación. Para la recolección de información se utilizaron dos grupos focales y se aplicó la técnica proyectiva sicopedagógica de manera individual. En general, es posible inferir que los sujetos presentan dificultades para percibirse como aprendices debido a los diferentes obstáculos que se presentan en el espacio escolar. Los jóvenes expresan no sentirse parte de la escuela, no ser sus saberes reconocidos, al mismo tiempo que presentan dificultades para establecer vínculos positivos con el personal docente.

Palabras clave: aprendizaje, juventudes, escuela (Tesauro de Ciencias Sociales de la Unesco).

Este artigo de investigação científica e tecnológica tem como base a investigação já concluída «O aprender como produção humana: os sentidos subjetivos produzidos acerca da aprendizagem por adolescentes em situação de vulnerabilidade social», apresentada pela primeira autora como requisito para obtenção de título de Mestre em Educação, orientada pela segunda autora, no Programa de Pós-graduação em Educação, na Pontifícia Universidade Católica do Rio Grande do Sul. Financiada pelo Conselho Nacional de Desenvolvimento Científico e Tecnológico, $\mathrm{n}^{\circ}$ do processo: 130868/2014-0, de $1^{\circ}$ de março de 2014 a 29 de fevereiro de 2016. O artigo se inscreve na área da Ciências da Educação e na Subárea da Educação Geral.

** Psicopedagoga. Mestre em Educação (Pontifícia Universidade Católica do Rio Grande do Sul-bolsista CNPq). Doutoranda em Educação pela Pontifícia Universidade Católica do Rio Grande do Sul, bolsista Capes. Professora convidada da Especialização em Psicopedagogia na Pontifícia Universidade Católica do Rio Grande do Sul. Orcid: 0000-0001-6923-2107. Correio eletrônico: juliana.rocha.001@acad.pucrs.br

*** Pedagoga. Mestre em Educação (Pontifícia Universidade Católica do Rio Grande do Sul). Doutora em Educação (Universidade Federal do Rio Grande do Sul). Professora titular do Programa de Pós-graduação em Educação da Pontifícia Universidade Católica do Rio Grande do Sul. Orcid: 0000-0001-8740-6166. Índice H5: 4. Correio eletrônico: Marlene.rozek@pucrs.br 


\section{When learning in school is (im)possible}

- Abstract (analytical): This present article presents the results of a thesis for a Master's in Education and aims to consider the subjective meanings and relations between teenagers. Ten teenagers, 14 to 18 years old, from Porto Alegre-Brazil participated in the research. To collect information, two focus groups were held and the Educational Peer psycho-pedagogical technique was applied individually. In general, it was possible to conclude that the teenagers face difficulty in learning at school due to the range of obstacles in the school space, which produces negative meanings related to formal education. The teenagers report that they do not feel like they are part of the school, they do not have their existing knowledge recognized in this space and they have difficulty in establishing healthy relationships with their teachers.

Key words: Learning, youth, school (Social Sciences Unesco Thesaurus).

\section{-1. Introdução. -2. Metodologia. -3. Achados da Pesquisa: quando aprender na escola é (im) possibilidade. -4.Considerações finais. -Referências.}

\section{Introdução}

Segundo a síntese de indicadores sociais da Pesquisa Nacional por Amostra de Domicílios (Pnad), do Instituto Brasileiro de Geografia e Estatística (Ibge), em 2012, 32,3\% da população brasileira de até 25 anos não tinha concluído o ensino médio e não estava estudando. Ainda segundo o documento, "o abandono escolar precoce atingia cerca de metade dos jovens de 18 a 24 anos de idade pertencentes ao quinto mais pobre $(53,8 \%)$ [da população], enquanto no quinto mais rico essa proporção era de apenas 10,2\%" (Instituto Brasileiro de Geografia e Estatística, 2013, p. 125). Nas últimas duas décadas, as taxas de analfabetismo têm diminuído e o ingresso na escola, aumentado. De acordo com a última Pnad publicada, ${ }^{1}$ de 2014, a taxa de analfabetismo de pessoas com mais de 10 anos é de 7,7\%. Entretanto, sabe-se que há grandes desafios no que se refere à permanência e aprendizagem de qualidade dos estudantes, o que se reflete no último Plano Nacional da Educação-PNE, com metas específicas para tais questões (Brasil, 2014). Desse modo, conhecer e compreender mais sobre a aprendizagem de jovens que se encontram em situação de vulnerabilidade social e pensar sobre as questões sociais implicadas nos processos de aprendizagem humana é imprescindível.

Assim, este texto se origina de uma investigação realizada durante o Mestrado em

1 Disponível em: http://brasilemsintese.ibge.gov.br/educacao/taxade-analfabetismo-das-pessoas-de-10-anos-ou-mais.html
Educação, que pretendeu investigar os sentidos subjetivos produzidos por jovens em situação de vulnerabilidade social acerca do aprender. Refere-se, então, a um recorte dos resultados do estudo e se propõe a refletir sobre os sentidos subjetivos e a relação dos/das jovens que participaram da pesquisa com a instituição escolar. Desse modo, tem-se o intuito de responder às seguintes questões: quais foram as aprendizagens mais significativas destes sujeitos ao longo de suas trajetórias de aprendizagem? Como relacionam o aprender com o processo de escolarização? Como se constrói o vínculo e as relações entre professores e estudantes no contexto escolar? Como alunos, alunas e profissionais da escola lidam com o tema «autoridade e limites»? E como essas relações influenciam as aprendizagens dos e das jovens?

Assim, objetiva-se refletir acerca de um aprender que se constitui pessoal e socialmente, sendo, por isso, influenciado pelas trajetórias do sujeito ao longo de sua vida: pelo contexto em que está inserido, pelas pessoas com as quais convive e pelas questões objetivas e subjetivas. Nessa perspectiva, o aprender é visto como um processo humano e «nenhuma vida humana [...] é possível sem um mundo que, direta ou indiretamente, testemunhe a presença de outros seres humanos» (Arendt, 2014, p. 31).

Partindo dessa concepção de aprendizagem, procurou-se compreender como o material participa da produção de subjetividade, visto que esse público específico apresenta um histórico de importantes percalços no processo 
de escolarização. Nesse sentido, entende-se que a subjetividade é objetiva na medida em que ocorre a partir da condição humana, da cultura em que o sujeito está inserido efetivamente, mas é subjetiva por ser uma produção psíquica, uma produção de sentidos subjetivos pelos quais o indivíduo expressa sua autonomia e sua criação em relação às interferências externas. Assim, é do processo dialético entre o social e o individual que a subjetividade se constitui (González-Rey, 2012).

A atividade humana, mediada socialmente, é produtora de significados e sentidos, partindo do social para o pessoal. As emoções e os processos simbólicos, organizados no decurso da experiência, não são isolados, têm como esteio a configuração subjetiva dessa experiência, na qual estão implicados subjetivamente todos os processos psíquicos que dela participam; é a intersubjetividade (González-Rey, 2012). O sentido subjetivo é uma produção do sujeito e refere-se ao corolário de uma trama de eventos e suas consequências, expressas em complexas produções psíquicas.

As juventudes são concebidas como uma construção social, circunscrita em diferentes e complexos contextos que proporcionam uma diversidade de trajetórias, portanto, é necessário que sejam antropológica e historicamente situadas nas sociedades contemporâneas. As desigualdades, diversidades e diferenças precisam ser reconhecidas de modo a enriquecer o diálogo com e sobre as juventudes nessa perspectiva (Abramovay, Castro, \& Waiselfisz, 2015).

Quanto à vulnerabilidade social, em suma, está relacionada à falta de acesso a bens culturais e artísticos, à dificuldade de estabelecer laços sociais, comunitários e familiares, bem como à precariedade e à dificuldade de acesso a serviços básicos, como saúde e educação. É a combinação de fatores como agravos à saúde, violência e pobreza, que pode deteriorar o nível de bem-estar das pessoas, famílias ou comunidades. Refere-se à vulnerabilidade do local onde os sujeitos estão inseridos, uma produção social, e não a uma característica própria da pessoa (Cronemberger \& Teixeira, 2012).
A pesquisa foi realizada entre os anos de 2014 e 2016. A amostra foi intencional, com a participação de 10 jovens, de 14 a 18 anos, residentes de um bairro de Porto Alegre, capital do Estado do Rio Grande do Sul (extremo Sul do Brasil), onde o narcotráfico é fortemente instituído; as famílias são, de modo geral, monoparentais e o acesso ao trabalho formal e a cultura é difícil. Para a coleta de dados foram utilizados dois grupos focais, formados por 5 participantes, e a técnica projetiva psicopedagógica Par Educativo, aplicada individualmente. Como técnica de análise utilizou-se a Análise Textual Discursiva-ATD (Moraes \& Galiazzi, 2011).

Destaca-se que, de modo geral, as aprendizagens reconhecidas socialmente são aquelas que ocorrem na escola. Esse aspecto torna difícil para os sujeitos da pesquisa perceberem-se como aprendentes, uma vez que enfrentaram inúmeros percalços no espaço escolar, produzindo sentidos subjetivos negativos em relação ao aprender formal. Os indivíduos não se sentem parte da escola, não têm seus saberes reconhecidos nesse espaço, apresentam dificuldade de vinculação com professores e professoras e relatam momentos em que vivenciam preconceito na escola. Entretanto, constata-se potencial para aprendizagem quando percebem-se em espaços com mais liberdade de expressão, flexibilidade e que proporcionem uma vinculação com ensinantes que permitam a sua circulação entre os espaços simbólicos de ensinante e aprendente.

\section{Metodologia}

A investigação, eleita como forma de aprofundar conhecimentos e de buscar respostas a perguntas que têm inquietado diferentes educadores em todo o país, foi baseada nos pressupostos da pesquisa qualitativa, que prioriza os processos e as relações estabelecidas entre os diferentes sujeitos da investigação e a realidade na qual estão inseridos. Nesse caso, «a realidade é um ponto de partida e serve como elemento mediador entre os sujeitos» (SánchezGamboa, 2012, p. 45); sujeito e realidade são indissociáveis. «O termo qualitativo implica 
uma partilha densa com pessoas, fatos e locais que constituem objetos de pesquisa, para extrair desse convívio os significados visíveis e latentes que somente são perceptíveis a uma atenção sensível» (Chizzotti, 2003, p. 221).

Apesar de surgir de uma realidade específica e buscar responder a questionamentos que surgem de uma prática no campo socioeducacional, ressalta-se que a pesquisa transcende a ideia de aplicabilidade, pois a complexidade do campo não pode ser reduzida a respostas simplistas; um cuidado a ser tomado pelos pesquisadores. Assim, não se pretende chegar a respostas prontas, mas instaurar um espaço que pense e discuta questões como aprendizagem, juventudes, sentidos subjetivos e vulnerabilidade social, a fim de que surjam novos questionamentos que impulsionem o campo educacional a buscar novas e diversificadas possibilidades para o enfrentamento dessas questões (André, 2007).

A pesquisa foi realizada com 10 jovens, ${ }^{2}$ de 14 a 18 anos -4 sujeitos do sexo masculino e 6 do sexo feminino-. A amostra foi do tipo intencional (Gil, 2008), assim, o nível de escolaridade e possíveis dificuldades de aprendizagem não foram parte dos critérios de seleção, uma vez que a pesquisa trata de aprendizagem humana e pretendeu compreender os sentidos subjetivos produzidos acerca da aprendizagem por jovens em situação de vulnerabilidade social, independentemente de suas trajetórias formais ou possíveis dificuldades de aprendizagem.

Todos os sujeitos são moradores de uma comunidade de Porto Alegre, instalada em um morro que fora escavado, em parte, como uma pedreira. As casas foram sendo construídas e dispostas de acordo com as possibilidades geográficas; algumas delas na parte mais alta, mas muitas na parte escavada, onde, em geral, ficam as residências em condições mais precárias -algumas sem banheiro ou água encanada-. O tráfico nessa área, um dos mais movimentados da Capital, fora comandado por um conhecido traficante, considerado pelo Departamento Estadual de Investigações do Narcotráfico (Denarc) como o mais forte representante do Comando Vermelho em Porto Alegre.

2 Pseudônimos foram utilizados para a identificação dos sujeitos.
Quanto à etnia, 90\% declaram-se negros e todos são naturais de Porto Alegre. A maioria das famílias é composta por apenas um adulto, adolescentes e crianças. Nessas famílias (com apenas um adulto), $71.4 \%$ dos adultos responsáveis são mulheres. Apenas 30\% dos responsáveis têm ensino médio completo; $50 \%$ não completaram o ensino fundamental.

Utilizaram-se duas técnicas para a coleta de dados: os grupos focais e a técnica projetiva psicopedagógica Par Educativo, ${ }^{3}$ aplicada individualmente. A coleta foi iniciada pela técnica individual, com o intuito de que desse momento surgissem dados importantes para iniciar a discussão dos grupos focais. Os adolescentes e as adolescentes foram divididos em dois grupos para a realização dos grupos focais, de acordo com a disponibilidade de horários. A coleta dos dados ocorreu de fevereiro a maio de 2015.

Quanto à análise, utilizou-se a Análise Textual Discursiva (ATD), que concerne a uma abordagem que, basicamente, transita entre duas técnicas da pesquisa qualitativa: análise de conteúdo e análise de discurso. A técnica pressupõe uma análise exaustiva dos dados, tendo como princípio a impregnação do pesquisador pelo corpus com o qual trabalha. Tem como orto a extenuante descrição acompanhada da cuidadosa interpretação. A ATD ocorre em três fases: unitarização, categorização e construção de metatextos (Moraes \& Galiazzi, 2011).

\section{Achados da pesquisa: quando aprender na escola é (im)possibilidade}

Compreender os sentidos subjetivos produzidos por jovens em situação de vulnerabilidade social acerca do aprender permite refletir sobre os processos de ensino e aprendizagem que ocorrem no âmbito escolar e,

3 Técnica utilizada para investigar o vínculo estabelecido pelos sujeitos com a aprendizagem e com o ensinante. Solicita-se ao indivíduo que desenhe uma pessoa ensinando e uma pessoa aprendendo. Posteriormente, é solicitado um relato sobre a cena e, por fim, pede-se que o sujeito faça uma história escrita sobre o desenho (Visca, 2002). As técnicas projetivas psicopedagógicas, em geral, podem contribuir significativamente no diagnóstico psicopedagógico, auxiliando na investigação dos diferentes vínculos estabelecidos pelos sujeitos, que se dão em três domínios: escolar, familiar e consigo mesmo (Visca, 2002). A técnica Par Educativo foi criada na Argentina e é amplamente utilizada no campo psicopedagógico; depois, também foi difundida no Brasil. 
também, nas aprendizagens externas à escola, na família e na comunidade. Ainda, é possível perceber como a interlocução entre as esferas da escola e da vida dos sujeitos pode facilitar ou dificultar processos saudáveis de aprendizagem.

As análises da pesquisa resultaram em suas categorias finais: Aprendizagem e Escola e Aprendizagem e Vida. Este texto centra suas análises para as relações dos sujeitos com as aprendizagens ocorridas ou não na instituição escolar.

$\mathrm{Na}$ perspectiva da aprendizagem humana, compreende-se o aprender como um processo complexo e dinâmico que ocorre ao longo da vida de todos os indivíduos, como condição e produção humana. Já o processo de escolarização, refere-se ao período em que os sujeitos são inseridos em um sistema institucionalizado, em que as aprendizagens são planejadas e organizadas de acordo com as diretrizes que regem o sistema de cada país, mas seguindo um padrão bastante geral e padronizado, hoje fortemente influenciado por agências e acordos internacionais.

A partir de uma organização social por interesses iniciada na Idade Média, que foi progressivamente se formalizando, surgiu a instituição escolar, que, aos poucos, conforme produzia acesso a bens materiais, tornou-se um espaço gerador de privilégios (Ariès, 1981). No Brasil, a escola como instituição também é marcada por uma história de reprodução do status quo. O país se constituiu a partir da premissa da dependência e exploração e «teve na educação o seu espelho mais fiel e o seu aparelho reprodutor mais eficaz» (Johann, 2008, p. 21). No século XVI, os jesuítas se tornaram responsáveis pela educação de nativos e, ainda que não tivessem a intenção, foram importantes para inculcar, também, a ideologia política de dependência. De acordo com Johann (2008), ao perceberem a ambiguidade de seu papel, os jesuítas se colocaram do lado de nativos e nativas, sendo, então, expulsos do país.

Desde então, foram quase quatro séculos de uma instituição escolar com ideologia religiosa, a serviço do poder político e econômico, e privilégio de poucos. Desse modo, o sistema educacional prestou-se como «reprodutor das estruturas de classe e das estruturas de poder»
(Johann, 2008, p. 24). Os primeiros passos em direção a uma reestruturação do sistema educacional ocorreram na década de 1930, na Era Vargas, com a instauração da República Nova e a criação do Ministério da Educação. Nessa época, a educação foi pensada como possibilidade de força de trabalho, e buscouse, então, ampliar o seu acesso para um número maior de pessoas.

A partir da década de 1960, o modelo de produção fordista entrou em crise e, com a chegada da Ditadura Militar, a internacionalização foi adotada pelo país em nome do progresso tecnológico. Nesse contexto, a educação passou a ser pensada a serviço do «capitalismo dependente» (Johann, 2008, p. 24). A escola torna-se um espaço em que os alunos e as alunas tem um papel passivo, onde são instruídos cívica, moral e conceitualmente, no qual o professor e a professora são detentores do saber e, consequentemente, do poder. Nessa lógica, as trajetórias dos sujeitos, suas aprendizagens fora da escola e suas condições de vida não são importantes. O que importa, de fato, é sua capacidade -inata- de absorver informações; um processo considerado básico e prioritariamente cognitivo.

Assim, países da América Latina e Caribe, campeões em desigualdade social, continuam a manutenção da pobreza, para a consequente manutenção da riqueza. De acordo com Nogueira (2013), essa desigualdade se reflete nas escolas por meio das relações entre docentes e estudantes, no tipo de material didático oferecido, nas estruturas físicas, na formação inicial dos profissionais e ofertas de formação continuada, na remuneração, etc.

Assim, é imprescindível refletir acerca de uma importante contradição que surge no grupo focal 2: quando a pesquisadora questiona sobre as características de um lugar ideal para aprender, Alli responde, sem pensar, que é a escola. Entretanto, salienta no fim do diálogo que já foi expulsa de quase todas as escolas que frequentou. Observa-se, ainda, que a jovem não frequentava a escola na época em que participou da pesquisa. Trata-se, então, de um sistema que tem o intuito de educar para o respeito, a diversidade e a liberdade (Brasil, 2014), que é concebido socialmente como «o» espaço para 
aprender, mas que reflete o viés mais cruel da questão social, oprimindo e inferindo que o aprender é somente para alguns, não para todos.

Esse lugar simbólico que Alli não «pode» ocupar na escola, o de quem aprende e faz parte do espaço escolar, reflete diretamente em suas percepções sobre o aprender. De modo geral, os sentidos subjetivos produzidos a respeito da aprendizagem estão muito relacionados às primeiras aprendizagens e aos vínculos estabelecidos com os primeiros ensinantes, mas também aos processos que ocorrem dentro da escola, principalmente quando o aprender está socialmente vinculado com a instituição, de forma que estar na escola, ter um certificado, confere o status de quem, de fato, aprende.

Assim, a legitimidade conferida a partir das aprendizagens formais torna-se uma barreira para que o sujeito se perceba como aprendente, quando os processos pelos quais passa na escola são tão cheios de fraturas. Os sentidos subjetivos mobilizados no momento de cada aprendizagem interferem no processo, de maneira positiva ou negativa, de acordo com a produção do sujeito. Ou seja, quando as vivências do aprender escolar são negativas, é grande a possibilidade de o sujeito evocar sentidos e emoções negativas quando aprende, pensa ou fala sobre o aprender.

Ainda hoje, muitas vezes a escola é reconhecida por desconsiderar as aprendizagens anteriores ao ingresso do sujeito no sistema, por preconceber alunos e alunas, esperando um público homogêneo, e por ignorar os aspectos subjetivos presentes nos processos de aprendizagem, assim como foi todo $\mathrm{o}$ movimento da ciência moderna. Desse modo, é comum que haja uma brusca separação entre a forma como cada sujeito se constituiu como aprendente desde sua infância -as matrizes de aprendizagem (Quiroga, 1996), os sentidos subjetivos produzidos acerca dos processose as propostas de ensino e aprendizagem do processo de escolarização, o que pode gerar uma importante fragmentação nos processos de aprendizagem.

Em contrapartida, os sujeitos relatam aprender a andar de bicicleta como uma de suas aprendizagens mais significativas. É perceptível que, apesar dos percalços encontrados nesse processo, os sentidos subjetivos produzidos a respeito dessa atividade foram positivos, relacionados ao prazer de dominar o próprio corpo e a bicicleta e de acompanhar os amigos, o que traz a sensação de pertença. Assim, as dificuldades não são evidenciadas, apesar de citadas, o que também traz maior satisfação, já que puderam ser superadas. O relato dos sujeitos culmina com o prazer e a felicidade que sentiram depois de aprender. Como refere Fernández (2001), o aprender e o ensinar precisam ser permeados pelo prazer de desfrutar a alegria compartilhada, em um processo que permita jogar com a autoria e correr os riscos.

Quando os sujeitos aprendem com os amigos a andar de bicicleta, há uma dinâmica nos papéis de quem ensina e de quem aprende. Essa possibilidade de constituir-se como ensinante traz a possibilidade de constituir-se como aprendente e vice-versa. Quando o sujeito aprende com aquele que, em outro momento, também aprende dele, há a compreensão da condição humana das duas figuras e, assim, ele pode se arriscar.

Voltando ao aprender na escola, mais uma vez aparecem as dificuldades, quando o aprender a ler e a escrever são citados. Nesse momento, torna-se perceptível a mudança dos sentimentos evocados a partir dessa aprendizagem: os relatos tornam-se breves e trazem, em sua maioria, aspectos negativos, como é possível perceber no seguinte trecho da fala de Mimosa, no grupo focal 1:

Eu fiquei a primeira série inteirinha sem saber escrever... Foi horrível! Bah, a professora parecia uma bruxa, meu. Ô, tô falando, serinho, ela pegava assim, pra mim escrever só a data e eu não fazia mais nada. [...] A maior parte sabia ler e quando vê eu só tinha que copiar a data: Porto Alegre... esses negócio assim. Era só isso.

Apesar de alguns sujeitos não inferirem maior dificuldade no processo, tampouco investem energia para relatá-lo ou trazem características positivas. $\mathrm{O}$ que a maioria salienta é que copiaram muito. Relatam que professores e professoras passavam matérias no quadro e eles copiavam. Nada novo, nada interessante, nada motivador aos processos de aprendizagem. 
Há um constante tensionamento entre a possibilidade de aprender e o espaço de impossibilidade encontrado quanto ao aprender formal. Entretanto, quando se valoriza socialmente apenas as aprendizagens mais conceituais, o sujeito, nessas condições, tende a se perceber como quem não pode aprender. De acordo com Parente (2008), é preciso que a escola encontre formas para que as aprendizagens formais tenham significado para as pessoas, de acordo com suas trajetórias de vida e suas necessidades.

Nesse sentido, para Fernández (2001a), as técnicas, os métodos e os procedimentos pedagógicos não são os mais importantes, mas a possibilidade de o professor sustentar o estudante durante o processo de aprendizagem, ou seja, outorgar-lhe o lugar de quem pode aprender. Nesse espaço, que precisa ser criado pela escola para que a aprendizagem ocorra de forma satisfatória, é preciso haver um ambiente propício para a criação, de forma que a espontaneidade dos sujeitos, desde os primeiros anos, não seja tolhida.

Para tanto, o vínculo, a relação que se estabelece na escola, os afetos, são de extrema importância. Entretanto, é também nessas relações que aparecem na pesquisa as dificuldades entre a aprendizagem e a escola. Em diferentes momentos dos grupos focais, e também na técnica do Par Educativo, tais questões são evidenciadas. Durante o debate no grupo focal 1, por exemplo, Desmondi lembra de um educador do Serviço de Convivência e Fortalecimento de Vínculos (SCFV), serviço que ele frequentava na instituição, dizendo que ele era um exemplo de profissional com o qual se aprende. Então, Aquilegia completa com a seguinte fala:

Tinha que ter professor assim como o Fabiano, ${ }^{4}$ que tem respeito. Ele é amigo, ele é professor. Quando ele tem que ser brincalhão, ele é brincalhão, quando ele tem que ser bravo, ele é bravo. Os professores eles dão toda a liberdade. Se o aluno manda ele «toma no cu», ele pega e manda também. Da onde que ele vai fazer isso? A partir do momento que ele

4 Trata-se de um nome fictício.

Rev.latinoam.cienc.soc.niñez juv 16 (1): 361-373, 2018 http://revistalatinoamericanaumanizales.cinde.org.co doi: $10.11600 / 1692715 \times .16122$ deu brecha pro aluno, vai ser assim. Vai ser assim...

Posteriormente se refere a outro professor: [...] ele era professor. Ele dava aula só quando ele queria. Se tivesse que mandar nós tomar no cu-desculpa!, ele mandava. [Habena concorda: Mandava!]

E, concluindo, Flora refere-se ao educador citado anteriormente:

Não era que nem o Fabiano. O Fabiano era um amigo. Que nem ele sempre falou pra nós: «aqui dentro eu vou ser professor, eu vou ser companheiro; lá fora a gente pode ser amigo». Até hoje se alguém tiver que conversar com o Fabiano pelo Face, a gente vai falar. [...] dele todo mundo gostava, todo mundo respeitava.

Tais trechos ilustram a fragilidade dos vínculos encontrados pelos sujeitos da pesquisa na escola. Durante os grupos focais, foi perceptível o quanto se sentem desrespeitadas e desrespeitados dentro da escola. Nesse sentido, a própria concepção social a respeito da juventude pode ser um percalço, quando considerada pela escola e pelos profissionais uma etapa fortemente demarcada por características negativas, de rebeldia, na qual a intenção de se posicionar pode ser considerada desafio, enfrentamento, desrespeito, etc. Assim, apenas pelo fato de serem jovens, sem levar em conta que se trata de um período constituído histórica e culturalmente, são considerados culpados por uma série de dificuldades encontradas no processo, que muitas vezes fazem parte da compreensão do adulto que os categorizam como «jovens problemáticos» (Esteves \& Abramovay, 2007). Infere-se, então, que a escola precisa considerar que os/as jovens têm suas características constituídas nas relações sociais e nas formas de sobrevivência que os grupos vão estabelecendo ao longo de suas trajetórias.

Nesse sentido, cabe inferir, ainda, que a forma como a sociedade percebe esses sujeitos também pode influenciar as relações entre professores, professoras e estudantes, visto que a escola reflete e se produz na sociedade. De acordo com Scherer (2015), a formação sóciohistórica brasileira contribui para o processo de «guetização» dos pobres, e coloca essa 
população como culpada pela realidade vivida, o que se revela em frases preconceituosas ditas pelos professores e relatadas pelos participantes da pesquisa.

Entretanto, sabe-se que os/as jovens também têm responsabilidade na relação que estabelecem com os ensinantes e, portanto, a pesquisadora os questiona sobre suas participações em tal contexto. Eles, por sua vez, conseguem perceber que também têm responsabilidade e que, muitas vezes, o professor e a professora, também são desrespeitados. Flora salienta:

Eu não sei... Se lembra antes quando a gente era do primeiro trabalho educativo? Quando entrou eu, o Alberto, Ítalo, a Gabriela, tudo? A gente era novo, a gente recém vinha do Sase, a gente só sabia incomodar mesmo. E a sora Alice e a Ju botaram a gente na linha. A gente não era mais aquelas crianças do Sase que ficava só incomodando, ficava enchendo o saco dos outros mais velhos. Não. A Alice dizia um ai pra gente... [...] A Ju também tinha autoridade com a gente e a gente vivia num ambiente legal de se aprender.

Ressalta-se que os sujeitos compreendem que a relação estabelecida na escola tem a sua contribuição, mas consideram a postura do professor para com eles de suma importância. Trata-se de sujeitos que não têm o respeito «gratuito» do outro, que convivem diariamente com o preconceito e, assim, precisam ser acolhidos em um ambiente escolar que lhes permita sentirem-se pertencentes e participantes, e não espectadores e estranhos.

Esse movimento não significa permitir que o educando faça o que quiser. Pelo contrário, significa ter autoridade, estabelecer regras claras e exequíveis. Toda a aprendizagem põe em jogo certo temor. $\mathrm{O}$ não saber causa angústia nas pessoas, mas de diferentes formas (Fernández, 2001). Contudo, todos têm certo nível de angústia durante os processos de aprendizagem. Para suportar esse sentimento, o vínculo com quem ensina é essencial. O companheirismo e amizade citados pelos sujeitos refletem a necessidade do afeto na aprendizagem.
Os vínculos são fundamentais para um processo de aprendizagem sadio, considerando que o sujeito se constitui aprendente a partir da sua relação com o ensinante e das posições subjetivas estabelecidas e ocupadas por quem ensina e por quem aprende desde as primeiras relações (Fernández, 2003). A aprendizagem é sempre um processo de troca, transmissão e construção entre ensinante e aprendente. De acordo com Fernández (1991), aprendese a partir do conhecimento do outro. Esse outro transmite parte do seu conhecimento e o aprendente o reorganiza, transformando-o para construir o seu. Entretanto, para poder transmitir esse «conteúdo» e para que o outro se aproprie dele, é necessário que haja um vínculo entre os dois.

$\mathrm{Na}$ aplicação da técnica psicopedagógica Par Educativo, foi possível perceber, mais uma vez, a dificuldade de vinculação que os sujeitos apresentam com o ensinante. De modo geral, mostram-se bastante resistentes à realização da técnica, com dificuldades para falar sobre o aprender, em especial sobre a aprendizagem formal, já que a técnica se direciona a recursos mais utilizados na escola, como o papel e o lápis, ou mesmo o desenho e a escrita. Os desenhos são bastante infantilizados, com poucos detalhes e figuras humanas primitivas, que, em geral, não se olham (não se comunicam), principalmente quando o desenho eleito pelo sujeito se refere ao aprender formal. De acordo com o conhecimento prévio da pesquisadora em relação à produção dos sujeitos, os desenhos apresentados estão significativamente abaixo de sua capacidade. Dos 10 sujeitos que realizaram a técnica, 4 representaram situações de aprendizagem não relacionadas à escola (3 relacionadas a futebol e 1 à música). Os demais são representações da aprendizagem formal.

No exemplo da Figura 1 é possível observar tais questões: hipóteses iniciais que em geral foram ratificadas a partir das questões trazidas nos grupos focais, algumas das quais aqui mencionadas. 
Figura 1. Desenho de Flora no Par Educativo.

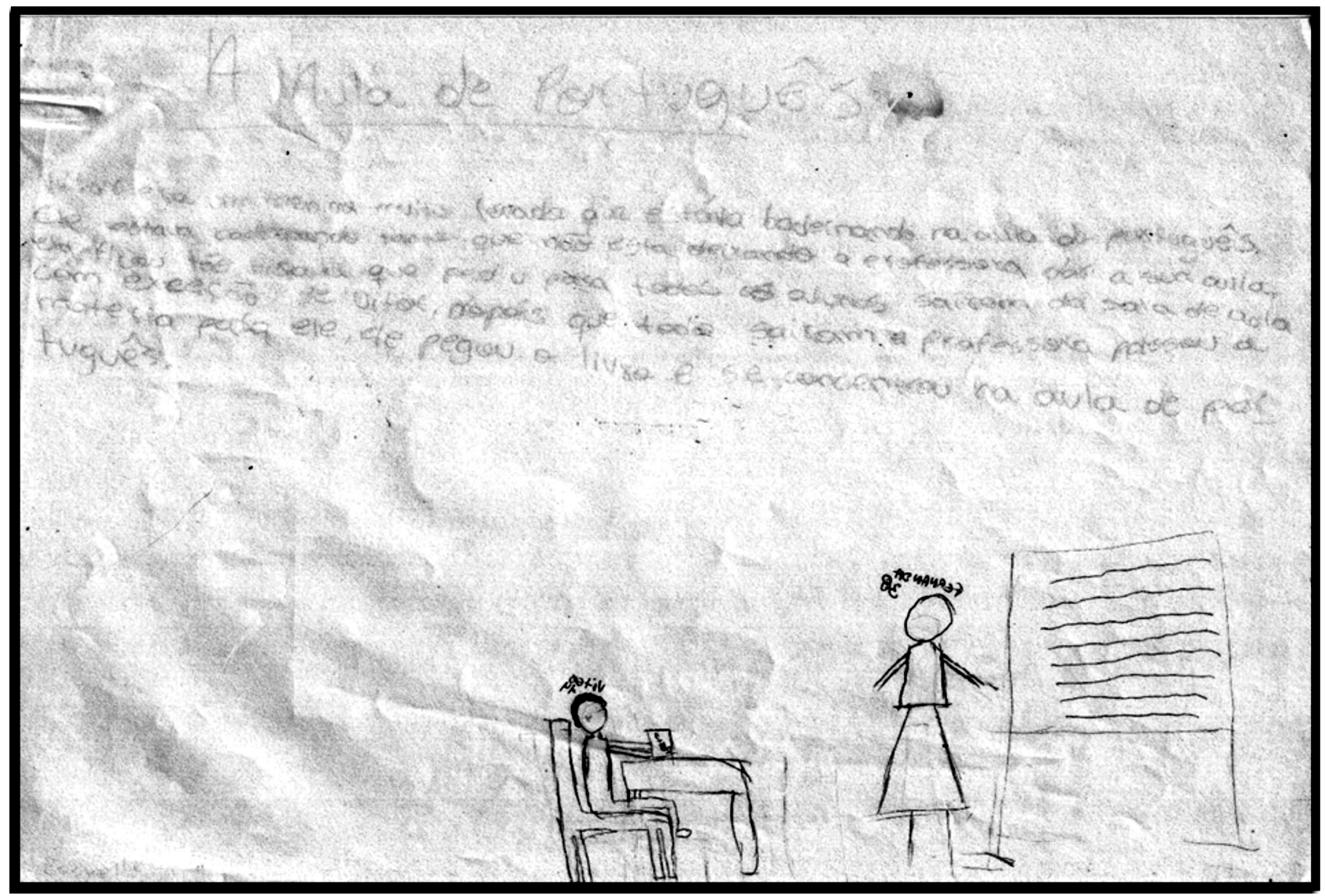

Fonte: dados da pesquisa de Rocha (2016).

Por exemplo, Flora, uma jovem de 17 anos, que apresenta bom diálogo e está na $2^{\mathrm{a}}$ série do ensino médio, mostra resistência para a realização da tarefa, porém a realiza. Desenha inicialmente o aluno e diz que está pronto. A pesquisadora pergunta: «Terminaste?». Ela diz que não. Retornando ao desenho, rabisca o ensinante, ainda com menos detalhes do que o aprendente. Esse certamente é um exemplo de produção abaixo da capacidade do sujeito, que demonstra clara dificuldade de vinculação com o ensinante e com o aprender. Inicialmente, a omissão do ensinante no desenho encaminha a hipótese de uma vinculação muito precária com essa figura e, portanto, uma difícil relação com professores em sua caminhada, visto que as próprias funções de ensinar e aprender constituem a relação professor-aluno (Oliveira, 2001) e que a própria Flora dá exemplos de uma difícil relação com professores ao longo de sua trajetória escolar.
Tratando-se de um conceito de subjetividade que ocorre social e individualmente, os processos de aprendizagem são influenciados tanto pelos sentidos subjetivos produzidos por alunos e alunas quanto pelos produzidos por professores e professoras, assim como os significados sociais dessas aprendizagens e o que a comunidade produz a respeito das aprendizagens formais e informais. Tal complexidade também se reflete nas relações entre docentes e estudantes, em um processo que se retroalimenta. Quando a comunidade escolar não permite que os sujeitos sejam ativos na construção do seu saber, quando eles não fazem parte da construção da própria instituição escolar, quando o outro que busca ensinar não é legitimado através dos vínculos, o aprender se torna mais difícil.

Contudo, ainda que os jovens considerem a necessidade de um outro para aprender, referem que às vezes o ensinante dificulta o processo, 
mais uma vez evidenciando a complicada relação que estabelece com professores e professoras. Cabem os exemplos a seguir:

Ela [a pessoa que ensina] ajuda ensinando aquilo que tu não sabe, e às vez atrapalha [...] Às vez ela atrapalha pegando no pé da pessoa, quando a pessoa pode às vezes tá certa e elas sempre querem tá certa e ela pode tá errada e ela não percebe isso daí. (AVE).

Sabe, ele tentava explicar do jeito dele e a gente tentava conversar. Ele não é daquele professor que, tipo... Tem gente que tem mais dificuldade realmente. $\mathrm{Eu}$ tenho mais facilidade em inglês, de repente a fulana não tinha facilidade, ao invés de ir lá: «Fulana, tô vendo que tu tá com dificuldade, vem aqui, eu vou te ajudar». Pra tentar ajudar ela, sabe? Não. E eu me indignava com aquilo. Ao invés de eu fazer o meu trabalho e focar no meu caderno, não. Eu ia lá e tentava ajudar a fulana que não tava entendendo a matéria. E eu me indignava com ele e discutia por causa disso, e dizia: «ela não ta entendendo e tu tem que ajudar ela porque tu é o professor». E ele: «se tu não gostou, tu ensina» (Flora).

Após essa última fala de Flora, a pesquisadora questiona se essa postura do professor é comum ou se apenas alguns agem dessa forma. Aquilegia responde que $95 \%$ dos professores e professoras são assim e todos os outros participantes confirmam.

Trata-se, pois, de um posicionamento de professores e professoras que distancia o aluno e a aluna e, consequentemente, dificulta que o aprendente se aproprie do conhecimento do outro, do ensinante. Nesse sentido, Fernández (1991) ressalta que, para que um sujeito faça do conhecimento do outro o seu próprio, é necessário que haja um jogo, um processo, uma relação de troca entre eles. O aprender ocorre em um lugar constituído pelo material e pela subjetividade dos sujeitos; é preciso que haja um espaço simbólico de confiança e criatividade.

Esse lugar pressupõe, por parte de quem ensina, um olhar para as possibilidades, que reconhece as dificuldades, mas busca encontrar caminhos para superá-las. Somente com essa perspectiva o educador terá a disponibilidade necessária para percorrer, junto com seus alunos e alunas, as trajetórias entre o não saber e o saber (Fernández, 2001). Contudo, a falta de interesse e o descrédito que tais profissionais têm quanto às possibilidades de aprendizagem dos alunos parecem refletir-se também na falta de estabelecimento de regras e combinações para facilitar as relações na escola. Nesse sentido, as seguintes falas exemplificam a visão dos sujeitos a respeito dos professores:

Na hora da prova até os professores tão gritando com os alunos (Desmondi).

Todo mundo agitado, ao invés dos professores colocarem ordem, não... (Flora).

O professor senta na mesa e começa a conversar com as pessoas. Tão nem aí! (Tillan).

É que hoje os professores também deixam as crianças fazerem o que quiser. Tu quer fazer tu faz, não quer fazer, não faz. Hoje tá bem assim! (Habena).

Não tem autoridade; a voz da autoridade [referindo-se aos professores] (Desmondi).

De acordo com Outeiral e Cerezer (2011), a autoridade é consentida ao sujeito e somente poderá ser outorgada ao professor a partir do estabelecimento de uma relação de confiança entre ele e o aluno. É um processo que necessita de investimento e paciência de ambas as partes. A autoridade é conferida por meio do poder legitimado pelo reconhecimento, pela aceitação e pelo respeito. Para tanto, professores e professoras precisam terum papel ativo atitudes coerentes. Autoridade também pressupõe afeto maduro, vigor, responsabilidade, credibilidade, empenho, influência e coerência. Sem esses atributos é mais difícil conquistar o respeito e ser uma figura de autoridade, que está autorizada a frustrar os sujeitos, mas, ainda assim, consegue manter uma relação estável, importante para a aprendizagem.

Esseéumprocesso trabalhoso, considerando que muitas vezes esses indivíduos passam boa parte do tempo em casa sem a participação de adultos, que têm longas jornadas de trabalho. Contudo, é necessário percorrer esse caminho 
em busca de relações regidas por acordos mútuos, regras claras, baseadas na confiança e jamais na ameaça. Em diferentes momentos do grupo focal 1, os participantes ressaltam que há muitas ameaças na escola. Flora fala brevemente sobre o tema:

Eles vivem muito de ameaça. «Eu vou te mandar pro $\mathrm{SOE},{ }^{5}$ vou te mandar pro SOE». Então manda, pelo amor de Deus. Eu incomodava só para ir pro SOE, só pra sair de dentro da sala de aula (Flora).

Assim, é evidente que a instituição escolar precisa articular suas ações, entre professores e equipes de apoio, para que todos possam traçar planos de intervenção que convirjam para os mesmos objetivos; nesse caso, estabelecer relações que possibilitem aos alunos e alunas outorgar autoridade aos profissionais da instituição.

A atualidade exige um "professor filtro». Trata-se daquele educador que desenvolve a capacidade de ser continente - de ser suportepara as demandas emocionais de alunos e alunas, sendo autoridade sem ser autoritário, criando, assim, um espaço seguro, no qual o sujeito compreenda a importância dos limites, apesar de nem sempre estar satisfeito com eles, mas, sobretudo, em que o limite seja entendido como cuidado e amor para com os aprendentes. Entretanto, destaca-se que essa deve ser a postura de todos os profissionais que fazem parte da escola, de forma que todos assumam, de fato, o papel de educador e a responsabilidade não seja delegada somente aos professores e professoras. Trata-se de uma demanda importante na contemporaneidade, em que as verdades, os valores e a ética são relativizados e sofre-se, como humanidade, uma crise (Outeiral \& Cerezer, 2011).

É importante que a escola, os educadores e as educadoras compreendam seu papel diante dos sujeitos pelos quais também são responsáveis. Ainda que a participação da família na educação de crianças e adolescentes tenha diminuído drasticamente, é necessário compreender que as exigências sociais também se modificaram. No entanto, isso não quer dizer

5 Serviço de Orientação Educacional.

Rev.latinoam.cienc.soc.niñez juv 16 (1): 361-373, 2018 http://revistalatinoamericanaumanizales.cinde.org.co doi:10.11600/1692715x.16122 simplesmente que a escola precisa absorver todas as demandas educacionais, mas que é necessário se adaptar à conformação social atual, sem esperar eternamente por uma modificação milagrosa. É necessário que a escola assuma suas responsabilidades como instituição educadora e tenha uma postura de firmeza com afeto para com alunos e alunas.

$\mathrm{O}$ aprender necessita de organização, cooperação, vinculação, espaço para o novo e para a criatividade, relacionamentos saudáveis, entre outros (Fernández, 2001, 2001a; Paín, 1999; Parente, 2008). Para tanto, a instituição escolar deve conhecer seus alunos e alunas, adequar-se às suas necessidades, construir parcerias e requerer dos estudantes sua participação, o que vai lhes mostrar a importância do seu papel na construção de uma escola mais participativa, mais democrática e mais justa.

\section{Considerações finais}

$\mathrm{O}$ processo de formalização das aprendizagens com a instauração da escola, ou seja, o reconhecimento social apenas das aprendizagens construídas e «oferecidas» pela instituição escolar desconsidera uma importante bagagem de aprendizagens e interesses que os/ as jovens inevitavelmente levam para a escola. As situações de vulnerabilidade social as quais estão expostos os/as jovens da pesquisa conformam especificidades nas trajetórias que precisam ser consideradas pela escola, para que esses sujeitos sintam-se pertencentes e sejam, de fato, partícipes dos processos escolares e de aprendizagem.

Com relação à escola, de modo geral, os sentidos subjetivos produzidos evidenciam uma emocionalidade que indica pouca confiança na potencialidade para o aprender. Os desenhos infantilizados, as dificuldades e angústias relatadas em relação ao aprender a ler e a escrever, a dificuldade de vinculação com os ensinantes e o medo de expulsão da escola são indicadores de sentidos subjetivos que se configuram voltados mais à impossibilidade do que à possibilidade de aprender.

As aprendizagens que aparecem como mais significativas ao longo das trajetórias dos 
sujeitos não estão relacionadas ao aprender da escola. Aprendizagens relacionadas às artes, como música, teatro e dança, que dão ao sujeito maior liberdade para expressar-se, e que ocorrem em um contexto mais flexível, que se constituiu junto com a comunidade e que busca adequar suas práticas às necessidades de vida dos sujeitos (a ONG), apareceram de forma mais positiva nos relatos. Cria-se um ambiente de possibilidade para o aprender, um espaço que permite a autoria, no qual as potencialidades dos sujeitos são consideradas e o trabalho em equipe permite a circulação entre os papéis de aprendente e ensinante, o que também ocorre no aprender a andar de bicicleta.

Contudo, torna-se necessária a instauração de um diálogo que provoque a superação de postulados da ciência moderna, que fragmentou o homem, e siga em direção à complexidade do humano; que compreenda a aprendizagem como condição e produção humana, construída de maneira dialética entre a história e a cultura humana e os aspectos próprios de cada sujeito, dada a irrepetibilidade do ser humano.

\section{Referências}

Abramovay, M., Castro, M. G., \& Waiselfisz, J. J. (2015). Juventudes na escola, sentidos e buscas: por que frequentam? Brasília: Flacso-Brasil, OEI, MEC.

André, M. (2007). Questões sobre os fins e sobre os métodos de pesquisa em educação. Revista Eletrônica de Educação, 1(1), 119131. doi:10.14244/198271996

Arendt, H. (2014). A condição humana. Rio de Janeiro: Forense universitária.

Ariès, P. (1981). História social da criança e da familia. Rio de Janeiro: LTC.

Brasil. (2014). Plano Nacional de Educação 2014-2024. Brasília: Câmara dos Deputados, Edições Câmara. Recuperado de: http://www.observatoriodopne.org.br/ uploads/reference/file/439/documentoreferencia.pdf

Cronemberger, I. M., \& Teixeira, S. M. (2012). Famílias vulneráveis como expressão da questão social e à luz da política de assistência social. Interface, 9(2), 92-117. Recuperado de: https://ojs.ccsa.ufrn.br/ojs//index.php?jour nal $=$ interface $\&$ page $=$ article \&op $=$ view $\&$ pa th $\% 5 \mathrm{~B} \% 5 \mathrm{D}=357 \&$ path $\% 5 \mathrm{~B} \% 5 \mathrm{D}=360$

Chizzotti, A. (2003). A pesquisa qualitativa em ciências humanas e sociais: evolução e desafios. Revista Portuguesa de Educação, 16(2), 221-236. Recuperado de: http:// www.redalyc.org/articulo.oa? $\mathrm{id}=37416210$

Esteves, C. G., \& Abramovay, M. (2007). Juventude, juventudes: pelos outros e por elas mesmas. In C. Esteves, \& M. Abramovay, Juventudes: outros olhares sobre a diversidade (pp. 19-54). Brasília: Ministério da Educação, Secretaria de Educação Continuada, Alfabetização e Diversidade; Unesco.

Fernández, A. (1991). A inteligência aprisionada. Porto Alegre: Artmed.

Fernández, A. (2001). O saber em jogo: a psicopedagogia propiciando autorias de pensamento. Porto Alegre: Artmed.

Fernández, A. (2001a). Os idiomas do aprendente: análise de modalidades ensinantes em famílias, escolas e meios de comunicação. Porto Alegre: Artmed.

Fernández, A. (2003). Los idiomas del aprendente: análisis de modalidades de enseñanza en familias, escuelas y medios. Buenos Aires: Nueva Visión.

Gil, A. C. (2008). Métodos e técnicas de pesquisa social. São Paulo: Atlas.

González-Rey, F. (2012). A configuração subjetiva dos processos psíquicos: avançando na compreensão da aprendizagem como produção subjetiva. En A. Martinez, B. Scoz, \& M. Castanho (Coords.), Ensino e aprendizagem: a subjetividade em foco (pp. 21-42). Brasília: Liber Livros.

Instituto Brasileiro de Geografia e Estatística. (2013). Sintese de indicadores sociais: uma análise das condições de vida da população brasileira (Estudos \& Pesquisas/32). Brasília: Diretoria de Pesquisas, Coordenação de População e Indicadores Sociais. Recuperado de: http:// biblioteca.ibge.gov.br/visualizacao/livros/ liv66777.pdf

Johann, J. R. (2008). Educação e a utopia da esperança. Canoas: Ulbra. 
Moraes, R., \& Galiazzi, M. C. (2011). Análise textual discursiva. Ijuí: Unijuí.

Nogueira, M. O. G. (2013). Educação, desigualdade e políticas públicas: a subjetividade no processo de escolarização da camada pobre. (Tese de Doutorado). Pontifícia Universidade Católica de São Paulo, São Paulo, Brasil.

Oliveira, I. M.(2001). O sujeito que se emociona: signos e sentidos nas práticas culturais. (Tese de Doutorado). Universidade Estadual de Campinas, Campinas, Brasil.

Outeiral, J. O., \& Cerezer, C. S. (2011). Autoridade e mal-estar do educador. São Paulo: Zagodoni.

Paín, S. (1999). A função da ignorância. Porto Alegre: Artes Médicas.

Parente, S. B. A. (2008). Encontros com Sara Paín. São Paulo: Vetor.

Quiroga, A. (1996). Matrices de aprendizaje: constitución del sujeto en el proceso de conocimiento. Buenos Aires: Cinco.

Rocha, J. (2016). O aprender como produção humana: os sentidos subjetivos produzidos acerca da aprendizagem por adolescentes em situação de vulnerabilidade social. (Dissertação de mestrado). Pontifícia Universidade Católica do Rio Grande do Sul, Porto Alegre, Brasil.

Sánchez-Gamboa, S. (2012). Pesquisa em educação: métodos e epistemologias. Chapecó: Argos.

Visca, J. (2002). Técnicas proyectivas psicopedagógicas y pautas gráficas para su interpretación. Buenos Aires: Visca \& Visca Editores. 